\title{
Sweet cherries from Fundão possess antidiabetic potential and protect human erythrocytes against oxidative damage
}

\author{
Ana C. Gonçalves ${ }^{a}$, Catarina Bento ${ }^{\text {a }}$, Branca M. Silva a , Luís R. Silva ${ }^{\mathrm{a}, \mathrm{b}, *}$ \\ ${ }^{a}$ CICS - UBI - Health Sciences Research Centre, University of Beira Interior, 6201-506 Covilhã, Portugal \\ b LEPABE - Department of Chemical Engineering, Faculty of Engineering, University of Porto, 4200-465 Porto, Portugal
}

\section{A R T I C L E I N F O}

\section{Article history:}

Received 15 December 2016

Received in revised form 16 February 2017

Accepted 26 February 2017

Available online 28 February 2017

\section{Keywords:}

Fundão region

Sweet cherry

Bioactive compounds

Phenolic compounds

Biological potential

\begin{abstract}
A B S T R A C T
Cherries are one of the most appreciated summer fruits due to their attractive colour, sweet taste, high water content, low level of calories and composition in bioactive compounds which, in turn, are important to prevent some pathologies like diabetes, cardiovascular diseases and cancer. In this work we evaluated the phenolic profile and biological potential of 5 varieties of sweet cherries from Fundão region (Portugal) (Saco, Sweetheart, Satin, Maring and Hedelfinger). A total of 23 phenolic compounds were identified by LC-DAD and distributed by the several classes: 6 anthocyanins, 1 hydroxybenzoic acid, 8 hydroxycinnamic acids, 3 flavan-3-ols and 5 flavonols. Maring revealed higher contents in anthocyanins, while Hedelfinger was the richest in non-coloured phenolics. The antioxidant capacity was evaluated against DPPH and nitric oxide radicals. Hedelfinger was the most active against $\mathrm{DPPH}^{*}\left(\mathrm{IC}_{50}=12.1 \mu \mathrm{g} / \mathrm{mL}\right)$ and Maring against nitric oxide $\left(\mathrm{IC}_{50}=140.9 \mu \mathrm{g} / \mathrm{mL}\right)$. Afterwards, antidiabetic capacity was evaluated through the inhibition of $\alpha$-glucosidase activity, pointing Hedelfinger as the most active $\left(\mathrm{IC}_{50}=10.3 \mu \mathrm{g} / \mathrm{mL}\right)$. The capacity of Saco extracts to inhibit the hemoglobin oxidation and the hemolysis of human erythrocytes was also evaluated. Both assays revealed a concentration-dependent inhibitory effect $\left(\mathrm{IC}_{50}=38.6 \mu \mathrm{g} / \mathrm{mL}\right.$ and $\mathrm{IC}_{50}=73.0 \mu \mathrm{g} / \mathrm{mL}$, respectively). The results obtained in this study allow us to conclude that sweet cherries possess a great biological potential, and further investigation should be done to promote commercialization and encourage its use in food supplements and in new pharmaceutical and nutraceutical applications.
\end{abstract}

(C) 2017 Published by Elsevier Ltd.

\section{Introduction}

In the last few years the increasing reports about a balanced diet, rich in fruits and vegetables, have shown this to be a good source of phytochemicals with great antioxidant capacity which is associated with improved health, playing also an important role in the prevention of chronic diseases, like cardiovascular diseases, Alzheimer's disease, diabetes and cancer (Slavin \& Lloyd, 2012). Sweet cherries (Prunus avium Linnaeus (L.)) are one of the fruits that have been largely studied, belonging to the same genus and family of peaches, apples, apricots and plums. In Portugal there is a long tradition of cultivating cherries, particularly in the northeast of the country, in county of Fundão, producing around 15,000 tons of cherries annually (Serra, Duarte, Bronze, \& Duarte, 2011). They are mainly consumed as fresh, alternatively they can be processed and commercialized alone or incorporated in several products, such as dry (with or without sugars), frozen, jams,

\footnotetext{
* Corresponding author at: CICS - UBI - Health Sciences Research Centre, University of Beira Interior, 6201-506 Covilhã, Portugal.

E-mail address: luisfarmacognosia@gmail.pt (L.R. Silva).
}

concentrate juices, powdered and canned (Ferretti, Bacchetti, Belleggia, \& Neri, 2010).

Sweet cherries are characterized by a reduced level of calories, high contents of water (around 80\%) and absence of sodium. They also present a considerable content of organic acids, fibers, vitamins, potassium, fatty acids, and phytochemical compounds, like volatiles, carotenoids, flavonoids (flavonols, flavan-3-ols, flavanones, flavones and, anthocyanins), hydroxycinnamic and hydroxybenzoic acids (Duarte \& Silva, 2014). Among these compounds, special interest has been focused on polyphenols due their great capacity to capture reactive oxygen and nitrogen species, and also due to the strong anti-inflammatory activity shown (Serra et al., 2011). The presence of these compounds in sweet cherries is regulated by climatic conditions, genotype, fruit maturity and storage conditions (Gonçalves et al., 2004).

Several works reported that daily intake of sweet cherries alleviates gout and arthritis pain, neurological, gastrointestinal, tumoral and cardiovascular pathologies (Duarte \& Silva, 2014; Ferretti et al., 2010; Jakobek, Seruga, Novak, \& Medvidovic-Kosanovic, 2007), and prevents diabetes, since studies reported that some phenolic compounds can inhibit $\alpha$-glucosidase activity, described as an enzyme responsible for the digestion of carbohydrates in absorbable monosaccharides (Duarte \& 
Silva, 2014; Ferretti et al., 2010; Silva \& Teixeira, 2015; Teixeira \& Silva, 2013).

These findings suggest that sweet cherries can minimize the accumulation of free radicals and could be used as effective drugs or as functional food. Therefore, the aim of this work was to determine the coloured and non-coloured phenolic profile of five sweet cherries from Fundão region (Portugal) by liquid chromatography with diode array detection (LC-DAD) and evaluate their biological potential. The antioxidant activity was performed against $\mathrm{DPPH}^{\circ}$ and nitric oxide radicals ( ${ }^{\circ} \mathrm{NO}$ ), the $\alpha$-glucosidase inhibitory potential was also evaluated, and the protection against induced oxidative damage in human erythrocytes by sweet cherries was evaluated through microassays. As far as we know, this is the first study about the capacity of sweet cherries to inhibit $\alpha$-glucosidase enzyme, and to protect human erythrocytes against peroxyl radicals ( $\left.\mathrm{ROO}^{\circ}\right)$, concerning inhibition of hemoglobin oxidation and erythrocyte hemolysis.

\section{Materials and methods}

\subsection{Standards and reagents}

All chemicals used were of analytical grade. Cyanidin-3-O-glucoside, cyanidin-3-0-rutinoside, pelargonidin-3-O-rutinoside and peonidin-3$\mathrm{O}$-rutinoside were from Extrasynthese (Genay, France). 3-OCaffeoylquinic acid, $p$-hydroxybenzoic acid, $p$-coumaric acid, kaempferol-3-O-glucoside, quercetin, quercetin-3-O-rutinoside, quercetin-3-O-glucoside, quercetin-3-O-galactoside, catechin, epicatechin and caffeic acid were obtained from Sigma-Aldrich (St. Louis, MO, USA). 1,1-Diphenyl-2-picrylhydrazyl ( $\left.\mathrm{DPPH}^{*}\right), \beta$-nicotinamide adenine dinucleotide (NADH), phenazine methosulfate (PMS), nitrotetrazolium blue chloride (NBT), $\alpha$-glucosidase from Saccharomyces cerevisiae (type I, lyophilized powder), phosphate-buffered saline (PBS), trypan blue and 2,2'-azobis (2-ethylpropionamidine) dihydrochloride (AAPH) were purchased from Sigma-Aldrich (St. Louis, MO, USA). N-(1naphthyl)ethylenediamine dihydrochloride, sulfanilamide, 4-nitrophenyl-alpha-D-glucopyranoside (pNPG) and sodium nitroprusside dihydrate (SNP) were obtained from Alfa Aesar (Karlsruhe, Germany). Methanol and acetonitrile were from Fisher Chemical (Leicestershire, United Kingdom). Water was deionized using a Milli-Q water purification system (Millipore Ibérica, S.A.U., Madrid).

\subsection{Cherry samples}

Five sweet cherry cultivars ( $1 \mathrm{~kg}$ each), namely Saco, Sweetheart, Satin, Maring and Hedelfinger were collected from Fundão region (Portugal) at the same stage of ripeness, by hand, between May and June of 2015. The fruits were immediately transported to the laboratory facilities, where pits were removed and separated from the pulp. The cherries' pulp was immediately frozen with liquid nitrogen and maintained at $-20^{\circ} \mathrm{C}$. Then, they were lyophilized and powdered (mean particle size lower than $910 \mu \mathrm{m}$ ), being divided into three aliquots, extracted and analysed separately.

\subsection{Phenolic compounds}

\subsubsection{Extraction}

The non-coloured and coloured phenolic compounds were extracted according to the procedure described by Silva and Queiroz (2016), with some modifications. Aliquots of $1 \mathrm{~g}$ of powder sample were weighed and extracted with $20 \mathrm{~mL}$ of EtOH (70\%) along $2 \mathrm{~h}$, under stirring after flushing with nitrogen to avoid oxidations. This extract was centrifuged at $4000 \mathrm{rpm}$ during $10 \mathrm{~min}$. Subsequently, the material was again extracted during $15 \mathrm{~min}$ with $100 \mathrm{~mL}$ of EtOH (70\%). Both supernatants were evaporated to dryness under reduced pressure at $30{ }^{\circ} \mathrm{C}$. The resulting extract was dissolved with $50 \mathrm{~mL}$ of deionized water and placed into the column. The C18 solid-phase extraction (SPE) column
(70 mL/10,000 mg; Macherey-Nagel) was previously conditioned with $20 \mathrm{~mL}$ of ethyl acetate, $20 \mathrm{~mL}$ of ethanol and $20 \mathrm{~mL}$ of $0.01 \mathrm{~mol} / \mathrm{L}$ $\mathrm{HCl}$. After passing the sample (non-coloured and coloured phenolics), the column was washed with $3 \mathrm{~mL}$ of $0.01 \mathrm{~mol} / \mathrm{L} \mathrm{HCl}$. Then, fraction I (non-coloured phenolics) was eluted with $20 \mathrm{~mL}$ of ethyl acetate and placed in an erlenmeyer. Fraction II (anthocyanins) was eluted with $40 \mathrm{~mL}$ of ethanol containing $0.1 \% \mathrm{HCl}$ and placed in a second erlenmeyer. Both fractions were evaporated under reduced pressure, and the dried extracts obtained were re-dissolved with $4 \mathrm{~mL}$ of methanol (fraction I) and in $20 \mathrm{~mL}$ of acidified water, pH 3.0 (fraction II) using a membrane filter $(0.45 \mu \mathrm{m}) .20 \mu \mathrm{L}$ of each sample were analysed on a LC model Agilent 1260 system (Agilent, Santa Clara, California, USA) using a Nucleosil ${ }^{\circ} 100-5 \mathrm{C} 18$ column $(25.0 \mathrm{~cm} \times 0.46 \mathrm{~cm} ; 5 \mu \mathrm{m}$ particle size waters; Macherey-Nagel, Düren, Germany). Detection was achieved with an Agilent 1260 Infinity Diode Array Detector (DAD) using the ChemStation software supplied by Agilent Technologies (Waldbronn, Germany).

\subsubsection{Anthocyanins}

The method used for anthocyanins (fraction II) extraction was based on Silva and Queiroz (2016). The mobile phase consisted of water/ formic acid/acetonitrile (87:10:3, $v / \mathrm{v} / \mathrm{v}$; eluent $\mathrm{A})$ and water/formic acid/acetonitrile (40:10:50, $\mathrm{v} / \mathrm{v} / \mathrm{v}$; eluent $\mathrm{B}$ ) using a gradient program as follows: from $10 \%$ to $25 \%$ B ( $10 \mathrm{~min}$ ), from $25 \%$ to $31 \%$ B (5 min), from $31 \%$ to $40 \%$ ( $5 \mathrm{~min}$ ), from $40 \%$ to $50 \%$ B ( $10 \mathrm{~min}$ ), from $50 \%$ to $100 \%$ B ( $10 \mathrm{~min}$ ), from $100 \%$ to $10 \%$ B ( $5 \mathrm{~min}$ ). Total run time was $50 \mathrm{~min}$. Flow rate was $0.8 \mathrm{~mL} / \mathrm{min}$. The injection volume was $20 \mu \mathrm{L}$. The compounds in each sample were identified by comparing their retention times and UV-VIS spectra in the 200-600 nm range with the library of spectra previously compiled by the authors. Anthocyanin quantification was achieved by the absorbance recorded in the chromatograms relative to external standards at $500 \mathrm{~nm}$. Compounds unknown 1 and unknown 2 were quantified as cyanidin-3-0-rutinoside.

\subsubsection{Non-coloured phenolics}

The method for quantification of the non-coloured phenolics (fraction I) was previously described by Silva and Queiroz (2016). The mobile phase used is composed by $2 \%(\mathrm{v} / \mathrm{v})$ acetic acid in water (eluent A) and $0.5 \%(v / v)$ acetic acid in water and acetonitrile (50:50, $v / v$, eluent B). The solvent system starting with $10 \%$ of $\mathrm{B}$, and installing a gradient to obtain ( $24 \%$ B at $20 \mathrm{~min}, 30 \%$ B at $40 \mathrm{~min}, 55 \%$ B at $60 \mathrm{~min}, 70 \%$ B $65 \mathrm{~min}$, $80 \% \mathrm{~B}$ at $70 \mathrm{~min}$ ), $100 \% \mathrm{~B}$ at $75 \mathrm{~min}$, and maintain $100 \% \mathrm{~B}$ isocratic during $5 \mathrm{~min}$ ( $80 \mathrm{~min}$ ). The established solvent flow rate was $1.0 \mathrm{~mL} / \mathrm{min}$. The injection volume was $20 \mu \mathrm{L}$. Spectral data from all peaks were accumulated in the range of $200-400 \mathrm{~nm}$. Phenolic compound quantification was achieved through the absorbance recorded in the chromatograms relative to external standards at $280 \mathrm{~nm}$ for flavan-3-ols and hydroxybenzoic acids, $320 \mathrm{~nm}$ for hydroxycinnamic acids and $350 \mathrm{~nm}$ for flavonols. The compounds in each extract were identified by comparing their retention times and UV-VIS spectra with those of authentic standards. The hydroxybenzoic acid derivative was quantified as $\rho$ hydroxybenzoic acid. The 3-O-caffeoylquinic acid and hydroxycinnamic acid derivative were quantified as 5-O-caffeoylquinic acid. $p$-Coumaric acid derivative $1, p$-coumaroylquinic acid and $p$-coumaric acid derivative 2 were quantified as $p$-coumaric acid. Catechin derivative was quantified as catechin.

\subsection{Biological assays}

The extract used for the biological assays was obtained from the mixture of both fractions I and II used for the evaluation of the phenolic compounds described above. The fractions were dried, after which it was observed an average yield of $3.1 \pm 0.006 \%$ from the starting dry material. 


\subsubsection{Evaluation of antioxidant activity}

2.4.1.1. $\mathrm{DPPH}$ assay. The ability of sweet cherries extracts to act as free radical scavengers against $\mathrm{DPPH}^{*}$ was determined following a described procedure (Silva et al., 2014). For each extract, seven different dilutions were prepared, placed into a 96-well plate, and read at $515 \mathrm{~nm}$. Ascorbic acid was used as positive control. Three experiments were performed in triplicate.

2.4.1.2. Nitric oxide assay. The activity against ${ }^{\circ} \mathrm{NO}$ was determined as described in previous works (Silva et al., 2014). The chromophore formed with Griess reagent was read at $562 \mathrm{~nm}$. For each extract, seven different concentrations were prepared in a 96-well-plate. Ascorbic acid was used as positive control. Three experiments were performed in triplicate.

\subsection{2. $\alpha$-Glucosidase inhibitory activity}

The inhibition of $\alpha$-glucosidase activity was determined at $405 \mathrm{~nm}$, based on Ellman's method previously described (Silva \& Teixeira, 2015). For each extract, six different concentrations were tested. Acarbose was used to positive control. Three experiments were performed in triplicate.

\subsection{In vitro $\mathrm{ROO}^{\circ}$-induced oxidative damage in human erythrocytes}

For the evaluation of the in vitro $\mathrm{ROO}^{\circ}$-induced oxidative damage in human erythrocytes only one cultivar was used. Saco cherry was selected taking into consideration that it is the most important cultivar in the Fundão region.

\subsubsection{Isolation of human erythrocytes}

Venous human blood was collected from randomized patients of Centro Hospitalar of Cova da Beira (Covilhã), by antecubital venipuncture into $\mathrm{K}_{3}$ EDTA vacuum tubes. Erythrocytes were isolated based on the procedure described by Chisté, Freitas, Mercadante, \& Fernandes (2014). Briefly, the collected blood was transferred to sterile conic tubes $(15 \mathrm{~mL})$, mixed with $6 \mathrm{~mL}$ of PBS ( $\mathrm{pH} 7.4)$ and centrifuged at $1500 \times \mathrm{g}$ for $5 \mathrm{~min}$ at $4{ }^{\circ} \mathrm{C}$. After centrifugation, the supernatant was discarded; the erythrocytes were washed with $6 \mathrm{~mL}$ of PBS and centrifuged again. This procedure was repeated twice and the resulting supernatant was discarded. The number of cells (cells $/ \mathrm{mL}$ ) and viability (always above 98\%) were obtained by the Trypan blue exclusion method. The suspensions of isolated erythrocytes were kept on ice until use.

\subsubsection{Inhibition of hemoglobin oxidation}

The inhibition of hemoglobin $(\mathrm{Hb})$ oxidation was evaluated by monitoring the effects of the lyophilized Saco extract on the formation of metHb (Chisté, Freitas, Mercadante, \& Fernandes, 2014) after the reaction of oxyhemoglobin $\left(\mathrm{HbO}_{2}\right)$ with $\mathrm{ROO}^{\circ}$ generated by AAPH. The extract was dissolved in PBS (6.3-100 $\mu \mathrm{g} / \mathrm{mL}$, final concentration), mixed with the suspension of human erythrocytes $\left(1250 \times 10^{6}\right.$ cells $/ \mathrm{mL}$, final density) and incubated at $37{ }^{\circ} \mathrm{C}$ in a water-bath, for $30 \mathrm{~min}$, under slow agitation $(\approx 50 \mathrm{rpm})$. After incubation, AAPH $(50 \mathrm{mM}$, final concentration) was added to the media and then incubated in the same conditions described above for $4 \mathrm{~h}$. The entire volume of the reaction mixture was centrifuged at $1500 \times \mathrm{g}$ for $5 \mathrm{~min}$ at $4{ }^{\circ} \mathrm{C}$. The supernatant $(300 \mu \mathrm{L})$ was placed in a 96 -well plate and the absorbance was read at $630 \mathrm{~nm}$ (Mariutti, Rodrigues, Chisté, Fernandes, \& Mercadante, 2014). Five experiments were performed in duplicate.

\subsubsection{Inhibition of hemolysis}

$\mathrm{ROO}^{\circ}$ were generated by AAPH and the prevention of ROO-induced hemolysis of human erythrocytes was evaluated by monitoring the release of $\mathrm{Hb}$ after membrane disruption caused by the hemolytic process, according to the optimized procedure described by Chisté et al. (2014). Briefly, six different concentrations of the lyophilized Saco extract dissolved in PBS (16-500 $\mu \mathrm{g} / \mathrm{mL}$, final concentration) and the suspension of human erythrocytes $\left(1775 \times 10^{6}\right.$ cells $\left./ \mathrm{mL}\right)$ were incubated at $37^{\circ} \mathrm{C}$ in water-bath during $30 \mathrm{~min}$, under slow agitation $(\approx 50 \mathrm{rpm})$, followed by the addition of AAPH solution ( $17 \mathrm{mM}$ ) and incubated again for $3 \mathrm{~h}$ in the same conditions described before. After incubation, the entire volume of the reaction mixture was transferred to $1.5 \mathrm{~mL}$ connic microtubes and centrifuged at $1500 \times \mathrm{g}$ for $5 \mathrm{~min}$ at $4{ }^{\circ} \mathrm{C}$. The supernatant $(300 \mu \mathrm{L})$ was placed in a 96 -well plate and the absorbance was obtained at $540 \mathrm{~nm}$. Five experiments were performed in duplicate.

\subsection{Statistical analysis}

Statistical comparison was made using one-way ANOVA and the means were classified by Tukey's test at a 95\% level of significance. Differences were considered significant for $P<0.05$. To determine the correlation between the antioxidant activity methods and the contribution of the total phenols, Pearson's correlation coefficients were calculated. All analyses were performed using Graph Pad Prism Version 6.01.

\section{Results and discussion}

\subsection{Phenolic composition}

\subsubsection{Anthocyanins}

The analysis by LC-DAD allowed the identification of four compounds being quantified six anthocyanins: unknown 1 (1), cyanidin3-O-glucoside (2), cyanidin-3-O-rutinoside (3), unknown 2 (4), pelargonidin-3-O-rutinoside (5) and peonidin-3-O-rutinoside (6) (Fig. 1 and Table 1 ).

All of these compounds were previously described in sweet cherry cultivars (Ballistreri et al., 2013; Jakobek et al., 2007; Serra et al., 2011), except for both unknown 1 and 2, even though we cannot identify the compounds, they are here reported for the first time (Table 1). Despite the differences observed in the amounts of each anthocyanin, the analysed samples exhibited similar profile. The anthocyanin identified as unknown 1 was only identified in Saco and Hedelfinger (Table 1).

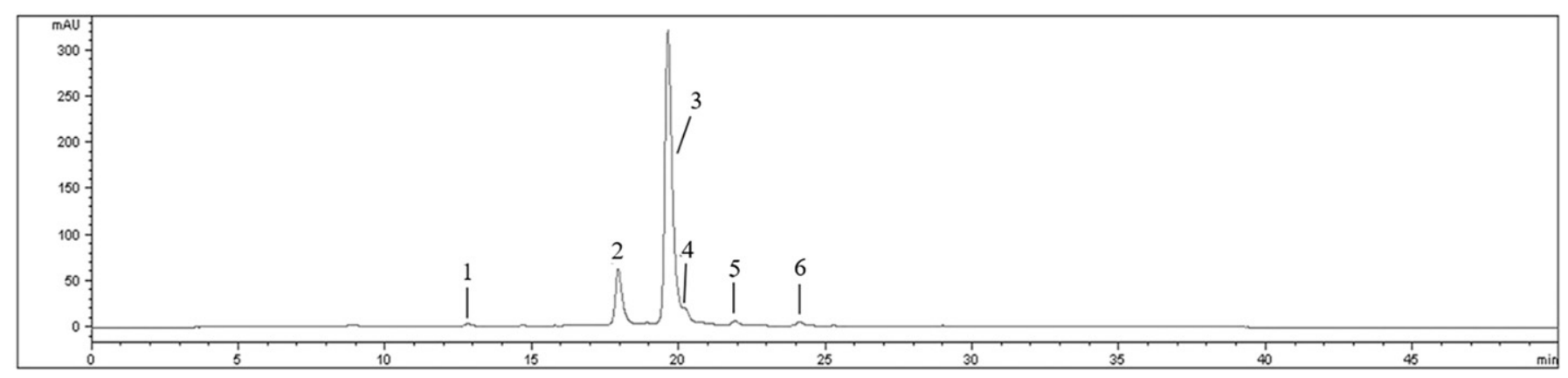

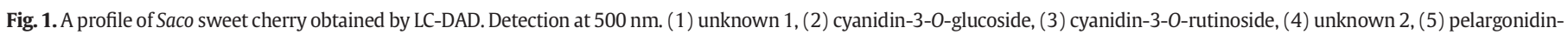
3-O-rutinoside and (6) peonidin-3-O-rutinoside, according to Table 1. 


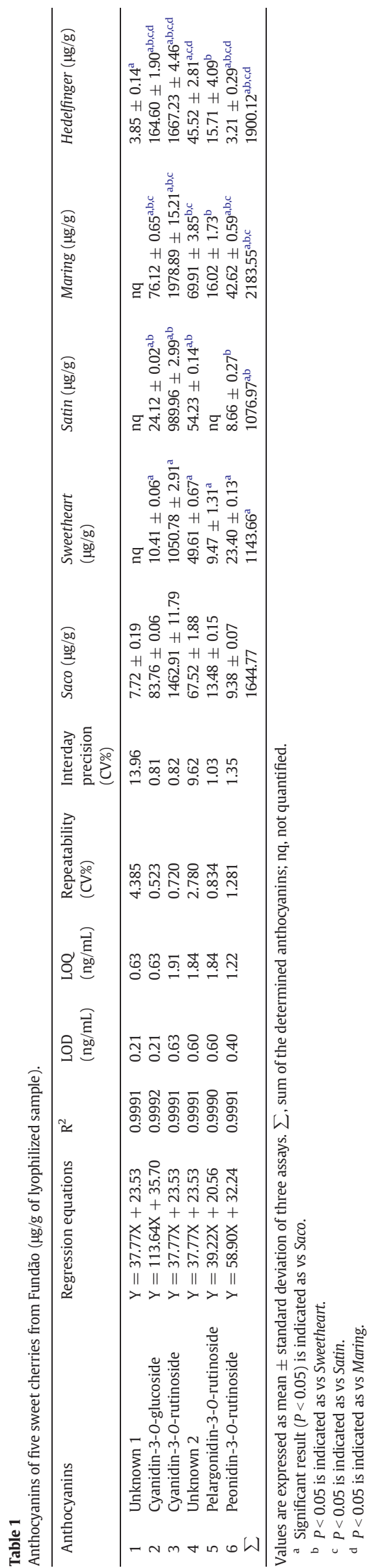

On the other hand, pelargonidin-3-O-rutinoside was identified in all samples, except in Satin (Table 1).

The linearity was obtained with standard solutions at seven different concentrations, selected as representative of the range of concentrations of the compounds in sweet cherries. The calibration plots showed a good correlation, as indicated by correlation coefficient $\left(R^{2}\right)$ with values higher than 0.99 for all anthocyanins (Table 1 ). The limit of detection $\left(\mathrm{LOD}=3 S_{0} / b\right)$, and limit of quantification $\left(\mathrm{LOQ}=10 S_{0} / \mathrm{b}\right)$ $\left(S_{0}\right.$ is the standard deviation of the signal-to-noise ratio of a low concentration standard and $b$ is the slope of the calibration curve) (Oliveira et al., 2010) are also shown in Table 1. The LOD and LOQ measured in sweet cherry cultivars ranged between 0.21 and $0.63 \mathrm{ng} / \mathrm{mL}$ and $0.63-1.91 \mathrm{ng} / \mathrm{mL}$, respectively. These results are in agreement with a previous work that presented LOD and LOQ for anthocyanins to be around 0.30 and $0.50 \mathrm{ng} / \mathrm{mL}$ and 0.10 and $1.25 \mathrm{ng} / \mathrm{mL}$, respectively (Sandhu, Edirisinghe, Burton-Freeman, \& Zweigenbaum, 2016).

To evaluate recovery, aliquots of cyanidin-3-O-rutinoside standard solution were treated with the same method and quantified by LCDAD, obtaining a recovery of $101.93 \pm 0.27 \%$. Repeatability was performed by analysing the same samples five times in the same day by the same analyst. The coefficients of variation obtained were lower than $5 \%$ (Table 1), proving that the repeatability of the procedure was satisfactory (Bayram, Ozcelik, Schultheiss, Frank, \& Rimbach, 2013). Furthermore, the interday precision was determined by analysing the samples on five different days (one injection per day), and coefficients of variation found were lower than $14 \%$ (Table 1 ), indicating that interday precision was within the established parameters.

The total amounts of anthocyanins ranging between 1076.97 and $2183.55 \mu \mathrm{g} / \mathrm{g}$ of lyophilized sweet cherries. Maring was the richest cultivar followed by Hedelfinger and Saco, being Satin the poorest one (Table 1). In a general way, our results are in accordance with Serra et al. (2011), where anthocyanins content varied between 560 and 3720 of $\mu \mathrm{g} / \mathrm{g}$ expressed as dry weight (dw) of fruit.

Cyanidin-3-O-rutinoside was the major compound identified in all sweet cherry cultivars, representing $87.7 \%-91.9 \%$ of total contents of anthocyanins, and $42.5 \%-68.6 \%$ of total phenolic compounds (Tables 1 and 2). Our data is in accordance with other previous works that reported cyanidin-3-O-rutinoside and cyanidin-3-O-glucoside as the main anthocyanins present in sweet cherries (Kelebek \& Selli, 2011; Serra et al., 2011). As far as we know, this is the first report about the anthocyanin profile of Satin cultivar.

Comparing the sweet cherries content with other red fruits, they were richer in anthocyanins than tart cherries (Prunus cerasus L.) (618.1 $\mu \mathrm{g} / \mathrm{g}$ expressed as dw), and also presented higher contents in cyanidin-3-O-rutinoside, however tart cherries presented other anthocyanins not reported in sweet cherries, such as cyanidin-3glucosylrutinoside and cyanidin-3-sophoroside (Seymour et al., 2008). The Portuguese red grapes namely Jaen, Alfrochadeiro and Syrah showed similar anthocyanin contents to sweet cherries, except Touriga, that showed two times more anthocyanins than the anthocyanin-rich Maring (Table 1). The main anthocyanin found in grapes was malvidin-3-O-glucoside (Silva \& Queiroz, 2016). Sweet cherries also showed a similar content to blackberry fruits (Rubus fruticosus L.) $(1760 \mu \mathrm{g} / \mathrm{g}$ expressed as dw). Cyanidin-3-O-glucoside was reported as the main one in these fruits, followed by cyanidin-3-xyloside, cyanidin-3-malonylglucoside, cyanidin-3-dioxalylglucoside and cyanidin-3-sambubioside (Zia-Ul-Haq, Riaz, De Feo, Jaafar, \& Moga, 2014).

\subsubsection{Non-coloured phenolics}

In respect to non-coloured phenolic compounds, the analysis of sweet cherries by LC-DAD allowed the identification and quantification of seventeen non-coloured different phenolics, comprising one hydroxybenzoic acid (1), eight hydroxycinnamic acids (peaks 2-4, 69 and 11), three flavan-3-ols (peaks 5, 10 and 12) and five flavonols (peaks 13-17) (Fig. 2 and Table 2). 

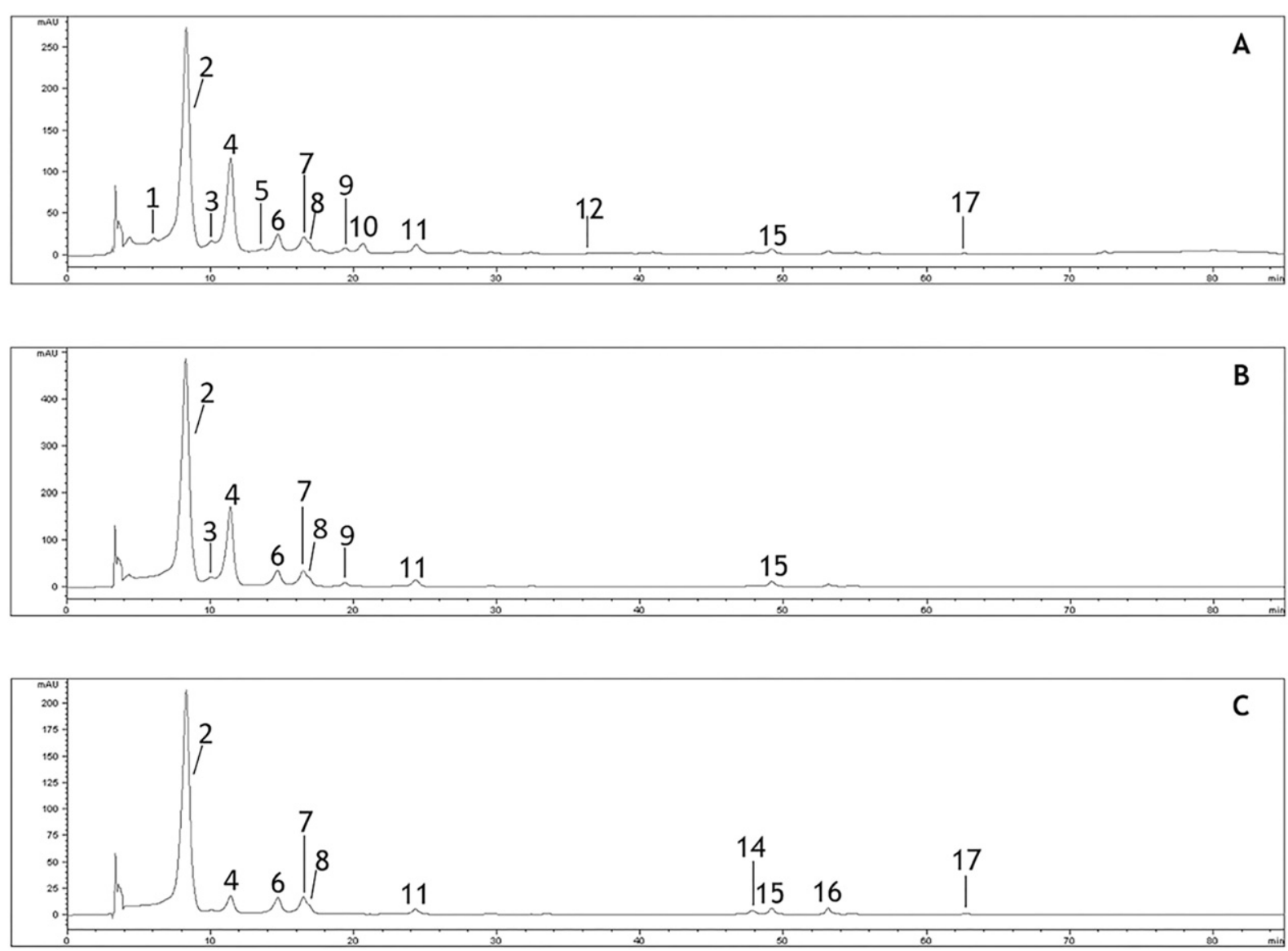

Fig. 2. Non-coloured phenolic profile of Saco sweet cherry obtained by LC-DAD. Detection at 280 (A), 320 (B) and $350 \mathrm{~nm}$ (C) according to Table 2.

All compounds were previously reported in sweet cherries (Bastos et al., 2015; Kelebek \& Selli, 2011; Serra et al., 2011), except quercetin-3-O-galactoside that was here reported for the first time. To confirm the presence of this compound, and using the same experimental conditions, we compared retention times and UV-VIS spectra with those of authentic standard. We obtained identical chromatograms where both had the same order of elution and identical UV spectra to our sweet cherry samples. Nevertheless, the five cultivars showed qualitative and quantitative differences (Table 2). Quercetin-3-O-galactoside was only detected in Maring and Hedelfinger. Additionally, $p$-coumaric acid and quercetin were only identified in Saco and Hedelfinger. Catechin was not detected in Satin and Hedelfinger.

Calibration curves were obtained with standard solutions at seven different concentrations, selected as representative for the range of compound concentrations in sweet cherries. The calibration plots showed a good correlation, as indicated by $\mathrm{R}^{2}$ values higher than 0.99 for all non-coloured phenolics (Table 2). The LOD and LOQ determined ranged between 0.16 and $1.18 \mathrm{ng} / \mathrm{mL}$ and $0.50-3.59 \mathrm{ng} / \mathrm{mL}$, respectively (Table 2). These results are in agreement with Bayram et al. (2013), who reported values between 0.03 and $1.70 \mathrm{ng} / \mathrm{mL}$ for LOD and 0.30 $5.40 \mathrm{ng} / \mathrm{mL}$ for LOQ.

To evaluate non-coloured phenolics recovery, aliquots of 5-Ocaffeoylquinic acid and quercetin-3-O-rutinoside were treated and quantified using the same method, obtaining a recovery of $86.10 \pm$ $0.045 \%$ and $100.39 \pm 1.81 \%$, respectively. Repeatability and interday precision were determined, and the coefficients of variation obtained were lower than $10 \%$ and $15 \%$, respectively (Table 2 ), indicating that the repeatability and interday precision of the procedure within the established parameters (Bayram et al., 2013).

The non-coloured phenolic contents of sweet cherry cultivars ranged between 389.10 and $2024.44 \mu \mathrm{g} / \mathrm{g}$ of dw, being Hedelfinger the richest one, followed by Saco and Maring. Sweetheart presented the lowest amounts in non-coloured phenolics, with five times less content than Hedelfinger and four times less than Saco (Table 2). Our results were similar to those obtained by Serra et al. (2011), where noncoloured content varied between 542 and $1957 \mathrm{of} \mu \mathrm{g} / \mathrm{g}$ of $\mathrm{dw}$. The same study, also reported that total flavonoid content in Saco was $1957 \mu \mathrm{g} / \mathrm{g}$, similar to that obtained in this work (Table 2).

Phenolic acids corresponded to 95.2, 93.6, 93.6, 90.7 and 86.3\% of total non-coloured phenolic compounds for Hedelfinger, Saco, Satin, Maring and Sweetheart, respectively (Table 2). The hydroxybenzoic acid derivative was the only hydroxybenzoic acid identified and quantified in all cultivars (Table 2). Relatively to hydroxycinnamic acids, they corresponded to $61.9-91.5 \%$ of the total non-coloured phenolic compounds, being 3-O-caffeoylquinic acid the major one found in all the studied cherry samples, except in Satin, where $\rho$-coumaroylquinic acid was the predominant hydroxycinnamate.

These results are in accordance with previous works which reported the 3-0-caffeoylquinic acid as the main non-coloured phenolic in Saco, Maring and Sweetheart cultivars (Hayaloglu \& Demir, 2016; Serra et al., 2011).

Concerning flavonoids (flavan-3-ols and flavonols), epicatechin (flavan-3-ol) was the one presenting higher amounts in Saco, corresponding to $3.2 \%$ of total amounts of non-coloured phenolics. On the other hand, quercetin-3-0-rutinoside (flavonol) was the most abundant in Sweetheart, Maring and Hedelfinger, ranging between 6.3, 2.9 and 2.2\% of total non-coloured phenolics, respectively. On the other hand, quercetin-3-0-glucoside (flavonol) was the main one in Satin, representing $1.6 \%$ of total non-coloured phenolics (Table 2). Flavonoids like epicatechin, catechin, quercetin-3-O-rutinoside and quercetin-3-O-glucoside were previously reported in sweet cherries Maring, Saco and Sweetheart (Hayaloglu \& Demir, 2016; Serra et al., 2011). As far as we know, this is 


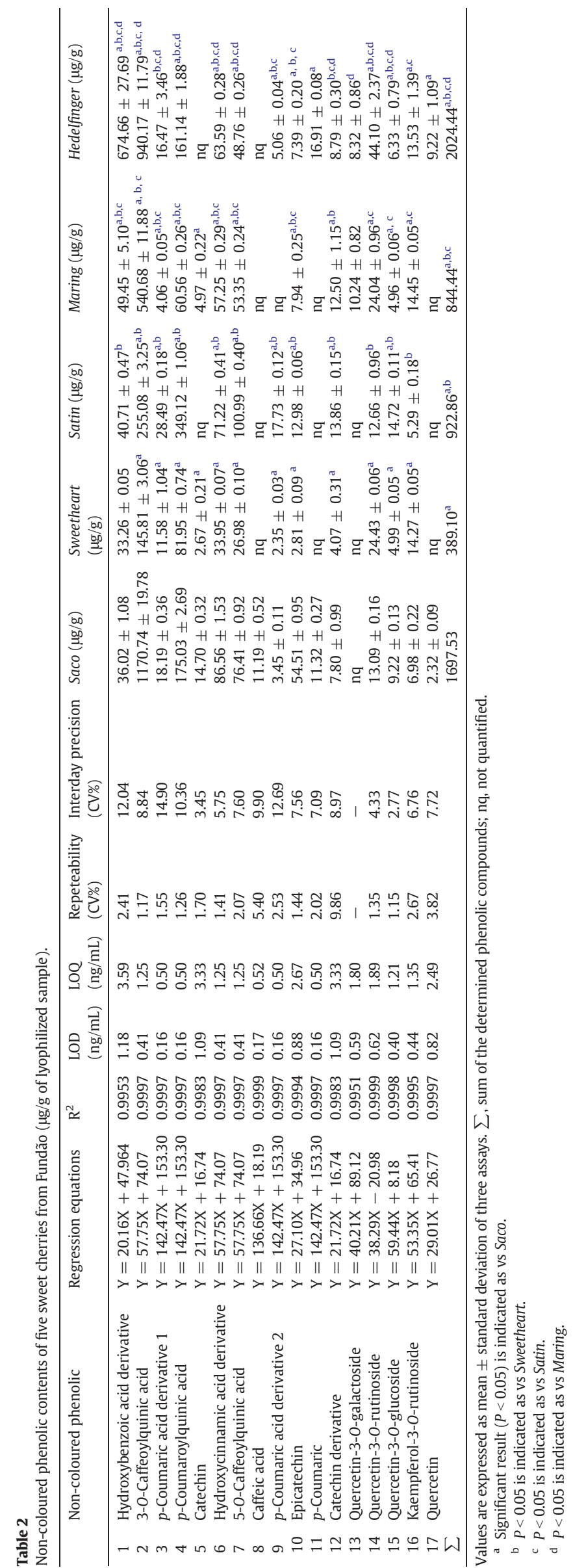

the first study that reported the non-coloured phenolic profile of Satin cultivar.

Comparatively with other red fruits, sweet cherries showed less amounts of non-coloured phenolics than tart cherries (5103-7813 $\mu \mathrm{g} / \mathrm{g}$ expressed as dw, respectively) (Kirakosyan, Seymour, Llanes, Kaufman, \& Bolling, 2009). Furthermore, tart cherries present isorhamnetin-3-Orutinoside (not identified in sweet cherries), quercetin and kaempferol as the main compounds (Seymour et al., 2008). Red grapes proved to be poorer than sweet cherries (ranged between 343.80 and $1328.30 \mu \mathrm{g} / \mathrm{g}$ expressed as dw), being more abundant in epigallocatechin, catechin and quercetin-3-0-glucoside (Silva \& Queiroz, 2016). As sweet cherries, blueberries (total amount of non-coloured phenolics $=26.700 \mu \mathrm{g} / \mathrm{g}$ expressed as dw) are very rich in hydroxycinnamic acids, mainly caffeic acid, but presenting lower amounts of quercetin than sweet cherries (Jakobek, Seruga, Seruga, Novak, \& Medvidović-Kosanović, 2009).

\subsection{Antioxidant potential}

Natural antioxidants present in fruits and vegetables have gained increasing interest among the scientific community and consumers, because epidemiological studies have indicated that regular consumption of natural antioxidants is associated with a lower risk of cardiovascular disease and cancer (Kelley, Rasooly, Jacob, Kader, \& Mackey, 2006; Miguel, 2011).

DPPH assay is routinely practiced for assessment of free radical scavenging potential of an antioxidant molecule, considered an easy standard colorimetric method for the evaluation of antioxidant properties of pure compounds and extracts, giving us a general screening of antioxidant potential (Ebrahimzadeh, Nabavi, Nabavi, Eslami, \& Rahmani, 2010; Teixeira \& Silva, 2013). All extracts exhibited a dose-dependent effect against DPPH${ }^{*}$. Hedelfinger, Satin and Saco were the most active $\left(\mathrm{IC}_{50}=12.1 \pm 0.37 ; 14.1 \pm 0.43\right.$ and $16.2 \pm 0.46 \mu \mathrm{g} / \mathrm{mL}$ of dried extract, respectively) (Fig. $3 \mathrm{~A}$ and Table 3 ), displaying similar activity to the positive control, ascorbic acid ( $\mathrm{IC}_{50}=16.92 \pm 0.69 \mu \mathrm{g} / \mathrm{mL}$ ).

Our values are in accordance with Prvulović, Popović, Malenčić, Ljubojević, and Ognjanov (2011), who reported that the aqueous:acetone (70:30) extract of Hedelfinger showed great capacity to scavenge DPPH (showing an activity of $86.94 \%$ at $0.02 \mathrm{~g} / \mathrm{mL}$ ). Comparatively with other red fruits, sweet cherries revealed a higher activity than blackberry Čačanska Bestrna fruits ( IC $_{50}$ ranged between 96.0 and $118.1 \mu \mathrm{g} / \mathrm{mL}$ expressed as dried aqueous extract) (Ivanovic et al., 2014), and less activity than calafate fruits, blueberries $\left(\mathrm{IC}_{50}=2.33 \pm 0.21 \mu \mathrm{g} / \mathrm{mL}\right.$ and $3.32 \pm$ $0.18 \mu \mathrm{g} / \mathrm{mL}$ expressed as dried aqueous extract, respectively) and strawberries (Fragaria $\times$ ananassa Duch.) $\left(\mathrm{IC}_{50}=7.6 \pm 2.1 \mu \mathrm{g} / \mathrm{mL}\right.$ expressed as dried aqueous extract) (Brito, Areche, Sepúlveda, Kennelly, \& Simirgiotis, 2014; Mandave, Rani, Kuvalekar, \& Ranjekar, 2013). Furthermore, the activities shown by Hedelfinger, Satin and Saco were similar to bilberries (Vaccinium myrtillus L.) ( $\mathrm{IC}_{50}=14.87 \pm 0.52 \mu \mathrm{g} / \mathrm{mL}$ expressed as dried methanolic extract) (Güder, Gür, \& Engin, 2015).

The extracts were then tested against ${ }^{\circ} \mathrm{NO}$, a free radical present in our organism and if overproduced has a negative impact in mitochondria and proteins, reacting with oxygen and superoxide reactive species, producing more toxic radicals like peroxynitrite and ROO; increasing cell damage. Additionally, it can activate pro-inflammatory transcription factors, causing neurodegenerative and chronic diseases, as rheumatoid arthritis, diabetes, atherosclerosis and cancer (Miguel, 2011; Silva et al., 2014). Along this assay all extracts exhibited a dose-dependent effect, being Maring, Saco and Hedelfinger $\left(\mathrm{IC}_{50}=140.91 \pm 1.85\right.$, $176.68 \pm 3.35$ and $185.11 \pm 1.52 \mu \mathrm{g} / \mathrm{mL}$ of dried extract, respectively) the most actives (Fig. 3B and Table 3), displaying similar effect when compared to positive control, ascorbic acid $\left(\mathrm{IC}_{50}=162.66 \pm\right.$ $1.31 \mu \mathrm{g} / \mathrm{mL}$ ). The positive effect of sweet cherry against ${ }^{*} \mathrm{NO}$ had already been proved in a study performed with eighteen healthy men and women, consuming $280 \mathrm{~g}$ daily of Bing sweet cherries during 28 days. The results revealed a significant reduction (about 18\%) in nitric oxide levels in the blood (Kelley, Rasooly, Jacob, Kader, \& Mackey, 2006). 

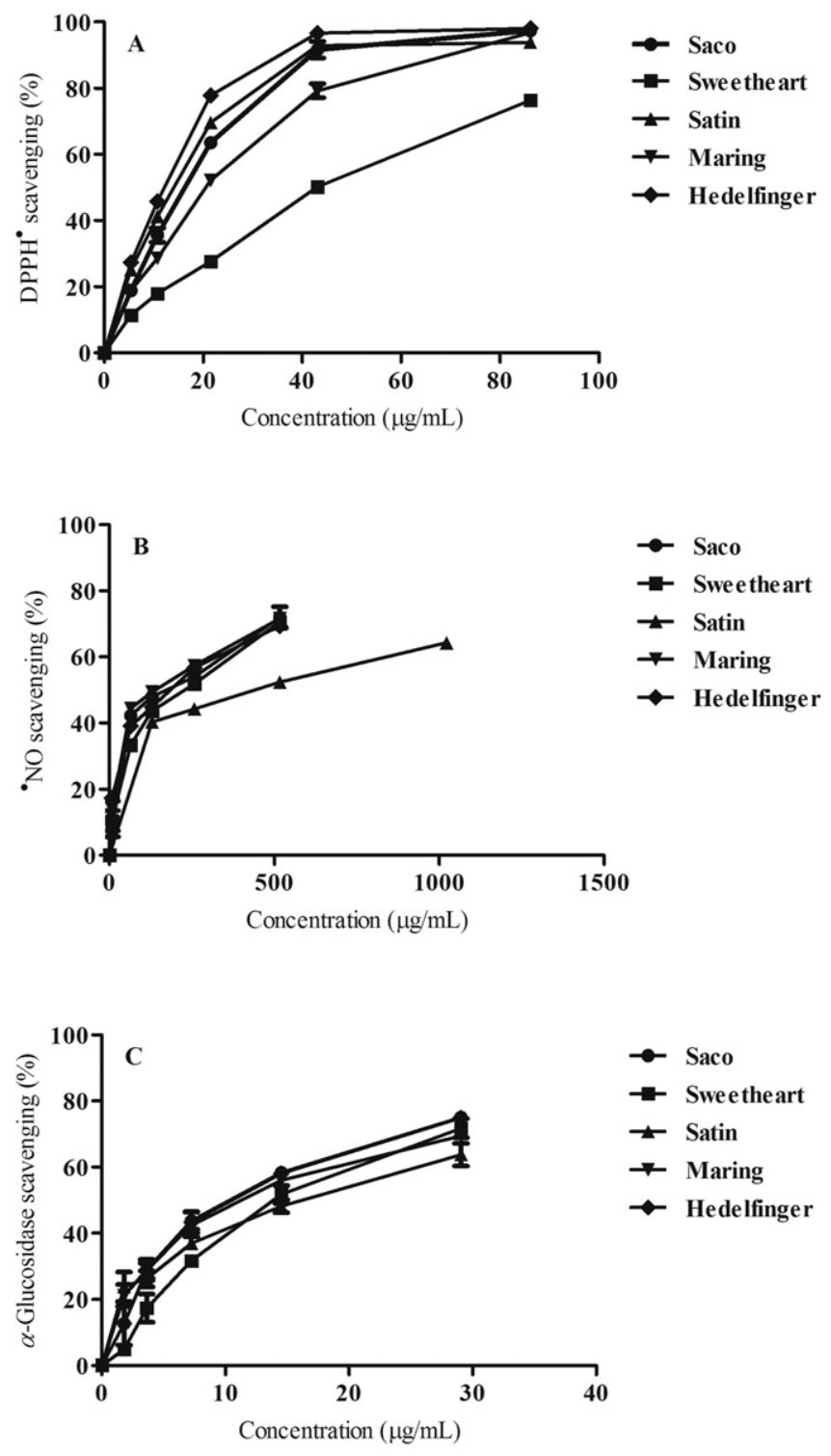

Fig. 3. Antioxidant activity against $\mathrm{DPPH}^{*}$ (A) and ${ }^{*} \mathrm{NO}(\mathrm{B})$, and $\alpha$-glucosidase inhibition activity (C) of sweet cherries extracts.

Our samples are less active than Indian sweet cherries $\left(\mathrm{IC}_{50}=21.1 \pm\right.$ $2.31 \mu \mathrm{g} / \mathrm{mL}$ expressed as dried ethanolic extract) (Bhattacharjee, Kamal, \& Roy, 2016), but more active than blueberries $\left(\mathrm{IC}_{50}=1500 \mu \mathrm{g} / \mathrm{mL}\right.$ expressed as dried ethanolic extract) (Samad, Debnath, Ye, Hasnat, \& Lim, 2014).

The antioxidant capacity of plant extracts is closely linked to their phenolic composition, whose anti-radical properties are known (Jakobek et al., 2007). In a general way, the antioxidant capacity of the fruits is proportional to their phenolic content: samples richer in phenolic content (particularly anthocyanins, flavonols, flavan-3-ols and phenolic acids) show bigger antioxidant activity (Kelebek \& Selli, 2011), as observed for Saco, Maring and Hedelfinger (Tables 1, 2 and 3 ). Phenolic compounds possess great antioxidant capacity due to their structure, where the hydroxyl $(\mathrm{OH})$ groups in unsaturated $\mathrm{C}$ ring, and also in the $3^{\prime}, 4^{\prime}$ and $5^{\prime}$ positions in $B$ ring increase the donation of hydrogen (Tadera, Minami, Takamatsu, \& Matsuoka, 2006). Anthocyanins, particularly cyanidin (and its glycosides), are great antioxidant molecules since they have more $\mathrm{OH}$ groups than the other compounds (Mendes, De Freitas, Baptista, \& Carvalho, 2011). As mentioned above, all of the antioxidant assays were performed with hydroethanolic extracts of each sample. Additionally, phenolics were the only compounds identified in those extracts. As so, in order to search for possible correlations between the determined compounds and the antioxidant capacity displayed by sweet cherries' extracts, Pearson's test was performed considering the $\mathrm{IC}_{50}$ values found in the both assays and the phenolic compounds content in each hydroethanolic extract. The results obtained indicate that the activity of all sweet cherries' extracts against DPPH ${ }^{\circ}$ and "NO was negatively correlated with the phenolic amounts. Nevertheless, individually, a little positive correlation was found between DPPH $^{*}$ test, kaempferol-3-O-rutinoside $(r=0.4760)$ and peonidin-30 -rutinoside $(r=0.4325)$. Additionally, $\rho$-coumaric acid derivative 1 ( $r=0.9444), \rho$-coumaroylquinic $(r=0.8646), \rho$-coumaric $(r=$ $0.8012)$ and 5-O-caffeolyquinic $(r=0.6441)$ acids, and quercetin-3-Oglucoside $(r=0.8640)$ showed positive correlation with "NO scavenging test. The possible presence of other non-determined active compounds like organic acids, volatiles, among others cannot be ignored, as they may contribute to increase the antioxidant potential.

\section{3. $\alpha$-Glucosidase inhibitory activity}

The search for natural sources to inhibit carbohydrate-hydrolyzing enzymes, as $\alpha$-glucosidase, increased due to their high potential for treating diabetes mellitus type 2 (Yin, Wang, Gu, Gu, \& Kang, 2012). The inhibition of this enzyme delays the absorption of ingested carbohydrates, reducing blood glucose levels and improving insulin sensitivity (Silva \& Costa, 2014).

As far as we know, this is the first report concerning the ability of sweet cherry extracts to inhibit $\alpha$-glucosidase activity. All tested extracts were able to inhibit this enzyme in a dose-dependent manner. Hedelfinger $\left(\mathrm{IC}_{50}=10.25 \pm 0.49 \mu \mathrm{g} / \mathrm{mL}\right.$ ) was the most active, followed by Saco $\left(\mathrm{IC}_{50}=10.79 \pm 0.40 \mu \mathrm{g} / \mathrm{mL}\right)$ and Maring $\left(\mathrm{IC}_{50}=11.38 \pm\right.$ $0.48 \mu \mathrm{g} / \mathrm{mL}$ ) (Fig. $3 \mathrm{C}$ and Table 3 ). The obtained $\mathrm{IC}_{50}$ values were much lower than positive control acarbose ( $\mathrm{IC}_{50}=306.66 \pm 0.84 \mu \mathrm{g} / \mathrm{mL}$ ), a drug commercialized as an enzyme inhibitor for type 2 diabetes, being reported several undesirable effects like intestinal pain, flatulence and diarrhea (Sathya \& Siddhuraju, 2012). The antidiabetic potential of sweet cherries was already reported in a study performed with diabetic rats that were fed with $200 \mathrm{mg}$ of fruit extract per kg body weight, during 30 days. After this time, all animals showed reduced blood glucose and urinary microalbumin levels, and also an increase of creatinine secretion, proving that sweet cherries consumption can protect pancreatic $\beta$-cells from damage, and also retard glucose absorption (Lachin, 2014).

Table 3

$\mathrm{IC}_{50}(\mu \mathrm{g} / \mathrm{mL})$ values found in the antioxidant activity and $\alpha$-glucosidase assays for sweet cherries dried extracts.

\begin{tabular}{|c|c|c|c|c|c|}
\hline Assay & Saco & Sweetheart & Satin & Maring & Hedelfinger \\
\hline $\mathrm{DPPH}^{\circ}$ & $16.24 \pm 0.46$ & $43.03 \pm 0.53^{\mathrm{a}}$ & $14.10 \pm 0.43^{\mathrm{b}}$ & $20.66 \pm 0.52^{a, b, c}$ & $12.12 \pm 0.37^{\mathrm{a}, \mathrm{b}, \mathrm{d}}$ \\
\hline NO & $176.69 \pm 3.35$ & $227.90 \pm 1.55^{\mathrm{a}}$ & $439.40 \pm 2.44^{\mathrm{a}, \mathrm{b}}$ & $140.91 \pm 1.85^{\mathrm{a}, \mathrm{b}, \mathrm{c}}$ & $185.11 \pm 1.52^{\mathrm{b}, \mathrm{c}, \mathrm{d}}$ \\
\hline$\alpha$-Glucosidase & $10.79 \pm 0.40$ & $14.34 \pm 0.56^{\mathrm{a}}$ & $16.31 \pm 0.71^{\mathrm{a}, \mathrm{b}}$ & $11.38 \pm 0.48^{\mathrm{b}, \mathrm{c}}$ & $10.25 \pm 0.49^{\mathrm{b}, \mathrm{c}}$ \\
\hline
\end{tabular}

Values are expressed as mean \pm standard deviation of three assays.

a Significant result $(P<0.05)$ is indicated as vs Saco.

b $P<0.05$ is indicated as vs Sweetheart.

c $P<0.05$ is indicated as vs Satin.

d $P<0.05$ is indicated as vs Maring. 
Comparatively with other red fruits, the inhibition of $\alpha$-glucosidase by sweet cherries superior to the activity reported for raspberries $\left(\mathrm{IC}_{50}=67.7 \mu \mathrm{g} / \mathrm{mL}\right.$ expressed as dried ethyl acetate extract) (Yin et al., 2012), strawberries ( $\mathrm{IC}_{50}=76.83 \pm 0.93 \mu \mathrm{g} / \mathrm{mL}$ expressed as dried aqueous extract) (Mandave et al., 2013) and bilberries (Vaccinium myrtillus $\mathrm{L}$. $)\left(\mathrm{IC}_{50}=138.41 \pm 1.05 \mu \mathrm{g} / \mathrm{mL}\right.$ expressed as dried methanolic extract) (Güder et al., 2015).

The positive results obtained for sweet cherries against $\alpha$-glucosidase may be attributed, at least partially, to their phenolic composition. Besides increasing antioxidant capacity, anthocyanins and non-coloured phenolics can inhibit $\alpha$-glucosidase activity in both competitive and non-competitive ways, enhancing antidiabetic properties (Tadera et al., 2006). In this work, a direct relation between the phenolic content and antidiabetic capacity was also observed. For example, Hedelfinger, in addition to having the highest phenolic content, also revealed the highest inhibitory activity of $\alpha$-glucosidase, followed by Saco (Tables 1 and 2).

\subsection{Protective effects of Saco extracts against $R O 0^{\circ}$ in human blood samples}

Erythrocytes are prime targets for free radical species owing to the presence of both high membrane concentration of polyunsaturated fatty acids and the oxygen transport closely linked with active hemoglobin molecules, which are promotors of reactive oxygen species (ROS) (Umbreit, 2007). Given so, in this experimental work and knowing the several benefits of detected cherry bioactive compounds, we evaluated for the first time the preventive effect of Saco sweet cherry extracts against $\mathrm{ROO}^{\circ}$-mediated toxicity generated by AAPH.

The oxidation of hemoglobin (resulting in methemoglobin ( $\mathrm{MHb}$ ), where the iron in the heme group is in the $\mathrm{Fe}^{3+}$ state and not as in normal state $\left(\mathrm{Fe}^{2+}\right)$ ) is not yet completely understood, but it is related to oxidative stress, in perturbations of protein interactions and damage in lipids, that makes the membrane of erythrocytes more susceptible to be degraded (Umbreit, 2007). MHb causes hipoxia events due to the inability of hemoglobin to bind or carry the oxygen, and causes an increase of ROS and reactive nitrogen species. $\mathrm{MHb}$ is also related to the lysis of erythrocytes and inflammatory processes, enhancing the release of interleukin (IL)-6 and IL-8, and E-selectin (adhesion molecule) at a cellular level (Umbreit, 2007).

Fig. 4A shows the protective effects of Saco extracts against hemoglobin oxidation in a concentration dependent manner $\left(\mathrm{IC}_{50}=\right.$ $38.57 \pm 0.96 \mu \mathrm{g} / \mathrm{mL}$ ). Saco extract showed values twelve times less effective than quercetin control $\left(\mathrm{IC}_{50}=3.10 \mu \mathrm{g} / \mathrm{mL}\right.$ ) analysed in the same conditions, reported as the most efficient phenolic compound against hemoglobin oxidation (Chisté et al., 2014).

Few studies were found about the capacity of fruit extracts to protect hemoglobin against oxidation. Relatively to other fruits, Saco extracts showed to be seven times more efficient to avoid hemoglobin oxidation than hydrophilic extracts of murici fruits (Byrsonima crassifolia), a fruit native to the North and Northeast regions of Brazil very rich in carotenoids (lutein and zeaxanthin), quercetin and gallic acid $\left(\mathrm{IC}_{50}=271 \pm\right.$ $44 \mu \mathrm{g} / \mathrm{mL}$ expressed as dried extract) (Mariutti et al., 2014).

The ability of flavonoids to prevent damage in erythrocytes is due to the $\mathrm{OH}$ substitutions: the more $\mathrm{OH}$ groups, greater the capacity of scavenging these reactive species. To highlight the cyanidin derivatives (with and without a sugar molecule) role, which in addition to possessing many $\mathrm{OH}$ groups, they can easily bind to the membrane of erythrocytes, improving its strength, and enhancing its protection against oxidation (Bonarska-Kujawa, Sylwia, Żyłka, Oszmiański, \& Kleszczyńska, 2014). Relatively to non-coloured phenolics, Kitagawa, Sakamoto, and Tano (2004) reported that numerous flavonoids present in Saco sweet cherry, particularly quercetin, quercetin glycosides and (-)-epicatechin, can inhibit the hemoglobin oxidation. These flavonoids are able to oxidize the heme iron of erythrocytes, thereby inhibiting their enzymatic reactions and preventing oxidation.
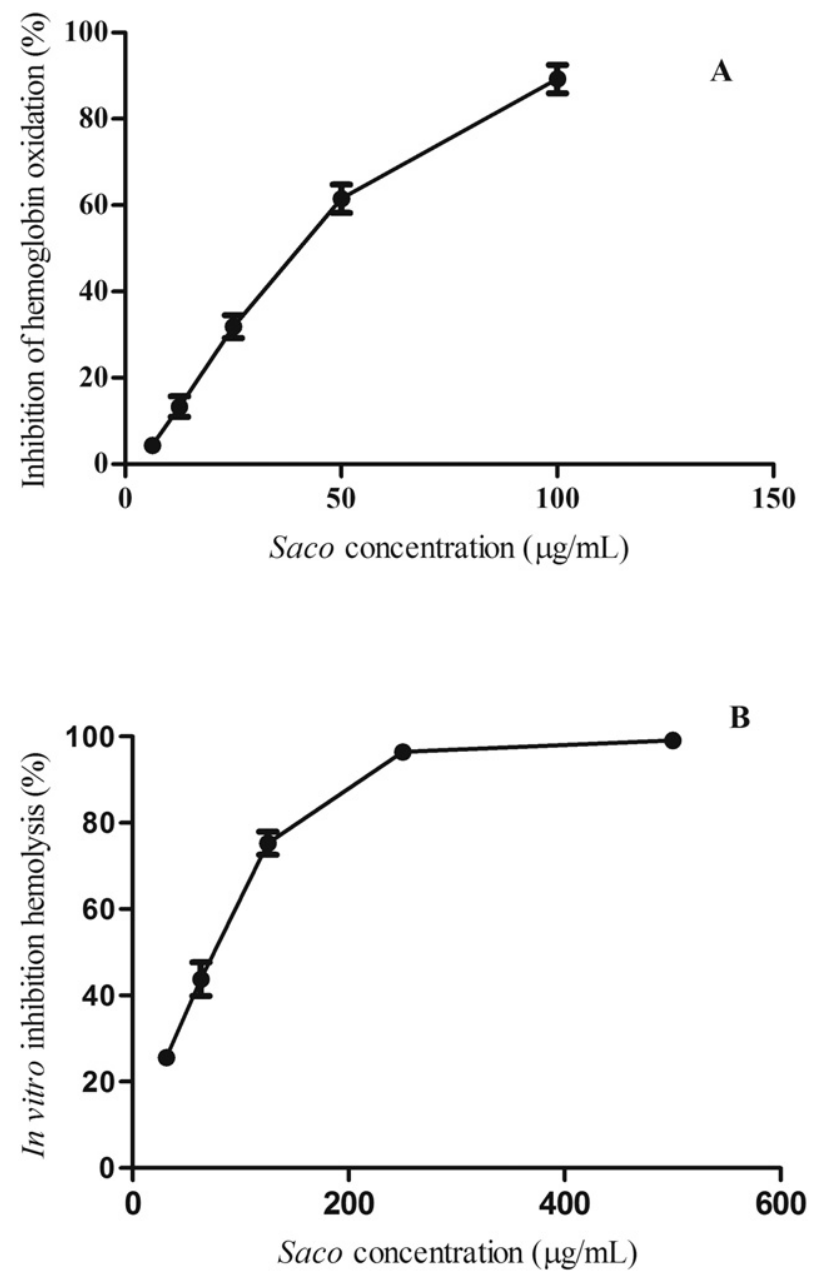

Fig. 4. Inhibition of hemoglobin oxidation (A) and hemolysis (B) by Saco sweet cherry extract.

ROO` generated by AAPH attacks the membrane of the erythrocytes from outside, leading to hemolysis. Saco extracts avoid hemolysis in a concentration dependent manner $\left(\mathrm{IC}_{50}=73.03 \pm 1.48 \mu \mathrm{g} / \mathrm{mL}\right.$ ) (Fig. $4 \mathrm{~B})$, proving efficiency to scavenge radical species in the medium before they can attack the erythrocytes, protecting them from lysis. Despite their protective potential, Saco revealed to be 104 times less effective than quercetin control (the most efficient phenolic for erythrocytes protection reported until now) analysed in the same conditions $\left(\mathrm{IC}_{50}=\right.$ $0.7 \mu \mathrm{g} / \mathrm{mL}$ ) (Chisté et al., 2014). Comparatively with other fruits, Saco sweet cherry proved to be five times more efficient than strawberry fruits (Arbutus unedo L.) ( $\mathrm{IC}_{50}=430.00 \mu \mathrm{g} / \mathrm{mL}$ expressed as dried aqueous extract) (Mendes et al., 2011), but six times less effective than Mexican grapes (Ruby Cabernet) ( $\mathrm{IC}_{50}=11.62 \mu \mathrm{g} / \mathrm{mL}$ expressed as dried methanolic extracts) (García-Becerra et al., 2016).

It is well known that flavonoids enhance erythrocytes' resistance against free radical species, mainly due to their capacity to capture them, by donating electrons. In addition, flavonoids also exhibit metalchelation properties, quenching radicals formed in the aqueous phase before they can damage the erythrocytes' membrane (Carvalho et al., 2010; Ebrahimzadeh et al., 2010), so it was expected that Saco was effective in the protection of erythrocytes against ROO ${ }^{\circ}$ generated by AAPH. These results are supported by another experimental work performed by Blasa, Candiracci, Accorsi, Piacentini, and Piatti (2007) which proved that phenolics protect the erythrocyte membrane due to its liposolubility. This allows them to be strongly incorporated into the membrane and act as antioxidant agents, leading to minimization of the concentration of reactive species. 


\section{Conclusion}

Considering the current interest in red fruits containing antioxidants and health-promoting phytochemicals as natural potential therapeutic agents, this work provides important information about the phenolic composition and biological potential of sweet cherries from Fundão (Portugal). A total of six anthocyanins and seventeen non-coloured phenolic compounds were quantified in sweet cherries, proving these to be a good source of bioactive compounds. Relatively to antioxidant activity, all samples showed great potential. Hedelfinger exhibited the best scavenging activity against $\mathrm{DPPH}^{*}$, and Maring proved to be more efficient against ${ }^{\circ} \mathrm{NO}$. Additionally, sweet cherries revealed great $\alpha$-glucosidase inhibitory activity, being more effective than the control acarbose. Furthermore, Saco proved to be able to inhibit hemoglobin oxidation and erythrocyte hemolysis in a concentration dependent manner, obtaining promising values during the assays. The phenolics found in sweet cherries contribute to the observed effects, playing an important role in the prevention of oxidation and cellular damage. As so, the consumption of these fruits can have great importance for attenuate/mitigate the development of human diseases associated with oxidative stress. Nevertheless, more studies are needed to unravel other positive benefits of sweet cherries in human health.

\section{Conflict of interest statement}

The authors have declared no conflict of interest.

\section{Acknowledgments}

This work is supported by FEDER funds through the POCI - COMPETE 2020 - Operational Programme Competitiveness and Internationalisation in Axis I - Strengthening research, technological development and innovation (Project POCI-01-0145-FEDER-007491), Operational Program of the Center (Project CENTRO-01-0247-FEDER-017547) and National Funds by FCT - Foundation for Science and Technology (Project UID/ Multi/00709/2013). Luís R. Silva (SFRH/BPD/105263/2014) was supported by post doc grants from FCT.

\section{References}

Ballistreri, G., Continella, A., Gentile, A., Amenta, M., Fabroni, S., \& Rapisarda, P. (2013) Fruit quality and bioactive compounds relevant to human health of sweet cherry (Prunus avium L.) cultivars grown in Italy. Food Chemistry, 140(4), 630-638.

Bastos, C., Barros, L., Dueñas, M., Calhelha, R. C., Queiroz, M. J. R. P., Santos-Buelga, C., \& Ferreira, I. C. F. R. (2015). Chemical characterisation and bioactive properties of Prunus avium L.: The widely studied fruits and the unexplored stems. Food Chemistry, 173, 1045-1053.

Bayram, B., Ozcelik, B., Schultheiss, G., Frank, J., \& Rimbach, G. (2013). A validated method for the determination of selected phenolics in olive oil using high-performance liquid chromatography with coulometric electrochemical detection and a fused-core column. Food Chemistry, 138(2-3), 1663-1669.

Bhattacharjee, M., Kamal, R., \& Roy, L. (2016). Evaluation of free radical scavenging activity of Prunus avium. International Journal of Pharmaceutical Sciences Review and Research, 38(2), 1-5.

Blasa, M., Candiracci, M., Accorsi, A., Piacentini, M. P., \& Piatti, E. (2007). Honey flavonoids as protection agents against oxidative damage to human red blood cells. Food Chemistry, 104(4), 1635-1640.

Bonarska-Kujawa, D., Sylwia, C., Żyłka, R., Oszmiański, J., \& Kleszczyńska, H. (2014). Biological activity of blackcurrant extracts (Ribes nigrum L.) in relation to erythrocyte membranes. BioMed Research International, 1-13.

Brito, A., Areche, C., Sepúlveda, B., Kennelly, E. J., \& Simirgiotis, M. J. (2014). Anthocyanin characterization, total phenolic quantification and antioxidant features of some chilean edible berry extracts. Molecules, 19(8), 10936-10955.

Carvalho, M., Ferreira, P. J., Mendes, V. S., Silva, R., Pereira, J. A., Jerónimo, C., \& Silva, B. M. (2010). Human cancer cell antiproliferative and antioxidant activities of Juglans regia L. Food and Chemical Toxicology, 48(1), 441-447.

Chisté, R. C., Freitas, M., Mercadante, A. Z., \& Fernandes, E. (2014). Carotenoids inhibit lipid peroxidation and hemoglobin oxidation, but not the depletion of glutathione induced by ROS in human erythrocytes. Life Sciences, 99(1-2), 52-60.

Duarte, A. P., \& Silva, B. M. (2014). Nutritional and phytochemical potential of "Prunus avium L.”. In V. K. Gupta (Ed.), Natural products: Research reviews. Vol. 4. (pp. 185-202). Nova Deli, India: M/S Daya Publishing House.
Ebrahimzadeh, M. A., Nabavi, S. M., Nabavi, S. F., Eslami, B., \& Rahmani, Z. (2010). Antioxidant and antihaemolytic activities of the leaves of Kefe cumin (Laser trilobum L) Umbelliferae. Tropical Journal of Pharmaceutical Research, 9(5), 441-449.

Ferretti, G., Bacchetti, T., Belleggia, A., \& Neri, D. (2010). Cherry antioxidants: From farm to table. Molecules, 15(10), 6993-7005.

García-Becerra, L., Mitjans, M., Rivas-Morales, C., Verde-Star, J., Oranday-Cárdenas, A., \& Vinardell María, P. (2016). Antioxidant comparative effects of two grape pomace Mexican extracts from vineyards on erythrocytes. Food Chemistry, 194, 1081-1088.

Gonçalves, B., Landbo, A. K., Knudsen, D., Silva, A. P., Moutinho-Pereira, J., Rosa, E., \& Meyer, A. S. (2004). Effect of ripeness and postharvest storage on the phenolic profiles of cherries (Prunus avium L.). Journal of Agricultural and Food Chemistry, 52(1), 523-530.

Güder, A., Gür, M., \& Engin, M. S. (2015). Antidiabetic and antioxidant properties of bilberry (Vaccinium myrtillus Linn.) fruit and their chemical composition. Journal of Agricultural Science and Technology, 17(2), 401-414.

Hayaloglu, A. A., \& Demir, N. (2016). Phenolic compounds, volatiles, and sensory characteristics of twelve aweet cherry (Prunus avium L.) cultivars grown in Turkey. Journal of Food Science, 81(1), C7-C18.

Ivanovic, J., Tadic, V., Dimitrijevic, S., Stamenic, M., Petrovic, S., \& Zizovic, I. (2014). Antioxidant properties of the anthocyanin-containing ultrasonic extract from blackberry cultivar "Čačanska Bestrna.". Industrial Crops and Products, 53, 274-281.

Jakobek, L., Seruga, M., Novak, I., \& Medvidovic-Kosanovic, M. (2007). Flavonols, phenolic acids and antioxidant activity of some red fruits. Deutsche Lebensmittel-Rundschau, 103, 369-378.

Jakobek, L., Šeruga, M., Šeruga, B., Novak, I., \& Medvidović-Kosanović, M. (2009). Phenolic compound composition and antioxidant activity of fruits of Rubus and Prunus species from Croatia. International Journal of Food Science and Technology, 44(4), 860-868.

Kelebek, H., \& Selli, S. (2011). Evaluation of chemical constituents and antioxidant activity of sweet cherry (Prunus avium L.) cultivars. International Journal of Food Science and Technology, 46(12), 2530-2537.

Kelley, D. S., Rasooly, R., Jacob, R. A., Kader, A. A., \& Mackey, B. E. (2006). Consumption of Bing sweet cherries lowers circulating concentrations of inflammation markers in healthy men and women. The Journal of Nutrition, 136(4), 981-986.

Kirakosyan, A., Seymour, E. M., Llanes, D. E. U., Kaufman, P. B., \& Bolling, S. F. (2009). Chemical profile and antioxidant capacities of tart cherry products. Food Chemistry, 115(1), 20-25.

Kitagawa, S., Sakamoto, H., \& Tano, H. (2004). Inhibitory effects of flavonoids on free radical-induced hemolysis and their oxidative effects on hemoglobin. Chemical \& Pharmaceutical Bulletin, 52(8), 999-1001.

Lachin, T. (2014). Effect of antioxidant extract from cherries on diabetes. Recent Patents on Endocrine, Metabolic E' Immune Drug Discovery, 8(1), 67-74.

Mandave, P., Rani, S., Kuvalekar, A., \& Ranjekar, P. (2013). Antiglycation, antioxidant and antidiabetic activity of mature strawberry (Fragaria $\times$ ananassa) fruits. International Journal of Applied Biology and Pharmaceutical Technology, 4(4), 168-177.

Mariutti, L. R. B., Rodrigues, E., Chisté, R. C., Fernandes, E., \& Mercadante, A. Z. (2014). The Amazonian fruit Byrsonima crassifolia effectively scavenges reactive oxygen and nitrogen species and protects human erythrocytes against oxidative damage. Food Research International, 64, 618-625.

Mendes, L., De Freitas, V., Baptista, P., \& Carvalho, M. (2011). Comparative antihemolytic and radical scavenging activities of strawberry tree (Arbutus unedo L.) leaf and fruit. Food and Chemical Toxicology, 49(9), 2285-2291.

Miguel, M. G. (2011). Anthocyanins: Antioxidant and/or anti-inflammatory activities. Journal of Applied Pharmaceutical Science, 1(6), 7-15.

Oliveira, A. P., Silva, L. R., Andrade, P. B., Valentao, P., Silva, B. M., Gonc-Alves, R. F., \& De Pinho, P. G. (2010). Further insight into the latex metabolite profile of Ficus carica. Journal of Agricultural and Food Chemistry, 58(20), 10855-10863.

Prvulović, D., Popović, M., Malenčić, Đ., Ljubojević, M., \& Ognjanov, V. (2011). Phenolic compounds in sweet cherry (Prunus avium L.) petioles and their antioxidant properties. Research Journal of Agricultural Science, 43(2), 198-202.

Samad, N. B., Debnath, T., Ye, M., Hasnat, M. A., \& Lim, B. O. (2014). In vitro antioxidant and anti-inflammatory activities of Korean blueberry (Vaccinium corymbosum L.) extracts. Asian Pacific Journal of Tropical Biomedicine, 4(10), 807-815.

Sandhu, A., Edirisinghe, I., Burton-Freeman, B., \& Zweigenbaum, J. (2016). UHPLC-MS/MS triple quadrupole analysis of anthocyanin metabolites in human plasma using protein precipitation and solid phase extraction for determination of Agilent Technologies.

Sathya, A., \& Siddhuraju, P. (2012). Role of phenolics as antioxidants, biomolecule protectors and as anti-diabetic factors - Evaluation on bark and empty pods of Acacia auriculiformis. Asian Pacific Journal of Tropical Medicine, 5(10), 757-765.

Serra, A. T., Duarte, R. O., Bronze, M. R., \& Duarte, C. M. M. (2011). Identification of bioactive response in traditional cherries from Portugal. Food Chemistry, 125(2), 318-325.

Seymour, E. M. Singer, A A M. Kirakosyan, A Urcuyo-Llanes, D. E, Kaufman, P. B. \& Bolling, S. F. (2008). Altered hyperlipidemia, hepatic steatosis, and hepatic peroxisome proliferator-activated receptors in rats with intake of tart cherry. Journal of Medicinal Food, 11(2), 252-259.

Silva, L. R., \& Costa, R. (2014). Health benefits of nongallated and gallated flavan-3-ols: A prospectus. Recent advances in gallate research. Vol. 20. (pp. 1-50). Nova Science Publishers.

Silva, L. R., \& Queiroz, M. (2016). Bioactive compounds of red grapes from Dão region (Portugal): Evaluation of phenolic and organic profile. Asian Pacific Journal of Tropical Biomedicine, 6(4), 315-321.

Silva, L. R., \& Teixeira, R. (2015). Phenolic profile and biological potential of Endopleura uchi extracts. Asian Pacific Journal of Tropical Medicine, 8(11), 889-897.

Silva, L. R., Azevedo, J., Pereira, M. J., Carro, L., Velazquez, E., Peix, A., \& Andrade, P. B. (2014). Inoculation of the nonlegume Capsicum annuum (L.) with Rhizobium strains. 1. Effect on bioactive compounds, antioxidant activity, and fruit. Journal of Agricultural and Food Chemistry, 62, 557-564. 
Slavin, J. L., \& Lloyd, B. (2012). Health benefits of fruits and vegetables. Advances in Nutrition, 3, 506-516.

Tadera, K., Minami, Y., Takamatsu, K., \& Matsuoka, T. (2006). Inhibition of $\alpha$-glucosidase and $\alpha$-amylase by flavonoids. Journal of Nutritional Science and Vitaminology, 52, 149-153.

Teixeira, R., \& Silva, L. R. (2013). Bioactive compounds and in vitro biological activity of Euphrasia rostkoviana Hayne extracts. Industrial Crops and Products, 50, 680-689.

Umbreit, J. (2007). Methemoglobin - It's not just blue: A concise review. American Journal of Hematology, 82, 134-144.
Yin, Z., Wang, J., Gu, X., Gu, H., \& Kang, W. (2012). Antioxidant and $\alpha$-glucosidase inhibitory activity of red raspberry (Harrywaters) fruits in vitro. African Journal of Pharmacy and Pharmacology, 6(45), 3118-3123.

Zia-Ul-Haq, M., Riaz, M., De Feo, V., Jaafar, H. Z. E., \& Moga, M. (2014). Rubus fruticosus L.: Constituents, biological activities and health related uses. Molecules, 19(8), 10998-11029. 